\title{
Étienne Langton. Prédicateur, bibliste, théologien, études réunies par Louis-Jacques Bataillon $\dagger$, Nicole Bériou, Gilbert Dahan et Riccardo Quinto
}

\section{G. Matteo Roccati}

\section{(2) OpenEdition}

Journals

Édition électronique

URL : http://journals.openedition.org/studifrancesi/2072

DOI : 10.4000/studifrancesi.2072

ISSN : 2421-5856

Éditeur

Rosenberg \& Sellier

Édition imprimée

Date de publication : 1 avril 2014

Pagination : 120

ISSN : 0039-2944

\section{Référence électronique}

G. Matteo Roccati, «Étienne Langton. Prédicateur, bibliste, théologien, études réunies par Louis-Jacques Bataillon †, Nicole Bériou, Gilbert Dahan et Riccardo Quinto », Studi Francesi [En ligne], 172 (LVIII | I) | 2014, mis en ligne le 01 avril 2014, consulté le 18 septembre 2020. URL : http://

journals.openedition.org/studifrancesi/2072 ; DOI : https://doi.org/10.4000/studifrancesi.2072

Ce document a été généré automatiquement le 18 septembre 2020.

\section{c) $($ ) $\odot$}

Studi Francesi è distribuita con Licenza Creative Commons Attribuzione - Non commerciale - Non opere derivate 4.0 Internazionale. 


\title{
Étienne Langton. Prédicateur, bibliste, théologien, études réunies par Louis- Jacques Bataillon $†$, Nicole Bériou, Gilbert Dahan et Riccardo Quinto
}

\author{
G. Matteo Roccati
}

\section{RÉFÉRENCE}

Étienne Langton. Prédicateur, bibliste, théologien, études réunies par Louis-Jacques BATAILLON $\dagger$, Nicole BÉRIOU, Gilbert DAHAN et Riccardo QUINTO, Turnhout, Brepols, 2010 («Bibliothèque d'histoire culturelle du Moyen Age», 9), pp. 694.

1 Le volume rassemble les communications présentées lors d'un colloque tenu au couvent Saint-Jacques à Paris en 2006. L'Avant-propos situe la figure d'Etienne Langton, «un auteur majeur, à cheval sur le $\mathrm{XII}^{\mathrm{e}}$ et sur le XIII ${ }^{\mathrm{e}}$ siècle, dont la production de bibliste, de théologien, de prédicateur constitue une étape importante dans l'histoire de la pensée médiévale» (p. 5). Les contributions sont organisées ensuite en quatre sections.

2 I. Étienne Langton dans l'histoire: John BALDwIN, Maître Étienne Langton, futur archevêque de Canterbury: les écoles de Paris et la «Magna Carta», pp. 11-50; Nicholas VINCENT, Stephen Langton, Archbishop of Canterbury, pp. 51-123; Rainer BERNDT, Etienne Langton et les victorins, ou l'embarras des lacunes, pp. 125-163; Valeria DE FRAJA, La ricezione delle opere di Stefano Langton nelle biblioteche cistercensi, pp. 165-197.

3 II. Étienne Langton, exégète de la Bible: Gilbert DAHAN, Les commentaires bibliques d'Étienne Langton: exégèse et herméneutique, pp. 201-239; Martin MORARD, Étienne Langton et les commentaires-fantômes: le cas du commentaire des Psaumes, pp. 241-284; Emmanuel BAIN, Etienne Langton, commentateur des Proverbes, pp. 285-326; Timothy Bellamah, The Lament of a Preacher: Stephen Langton's Commentarv "Super Threnos", pp. 327-352; Giovanna MURANO, Chi ha scritto le "Interpretationes hebraicorum nominun"?, pp. 353-371; Mark CLARK, 
The Commentaries of Stephen Langton on the "Historia scholastica" of Peter Comestor, pp. 373-393.

$4 \quad$ III. Étienne Langton, prédicateur: Nicole BÉRIOU, La prédication d'Étienne Langton. Un état de la question quarante ans après la thèse de Phyllis Roberts, pp. 397-425; Louis-Jacques BATAILLON $\dagger$, Les douze Prophètes enseignés et prêchés par Etienne Langton, pp. 427-447; Franco MORENZONI, Pastorale et ecclésiologie dans la prédication d'Étienne Langton, pp. 449-466; Anne-Zoé RILLON, Etienne Langton et la musique: implications musicales dans la prédication, pp. 467-484.

5 IV. Étienne Langton, théologien: Claire ANGOTTI, Étienne Langton, commentateur des «Sentences» de Pierre Lombard, pp. 487-523; Riccardo QUINTO, La constitution du texte des "Quaestiones theologiae», pp. 525-562; Luisa VALENTE, Logique et théologie trinitaire chez Etienne Langton: «res», «ens», «suppositio communis» et "propositio duplex», pp. 563-585; Magdalena BIENIAK, La place d'Etienne Langton dans le débat sur le concept de «persona», pp. 587-600; Christian TROTTMANN, Syndérèse et libre-arbitre dans les «quaestiones» d'Étienne Langton, pp. 601-622; Lauge O. NIELSEN, Langton's Questions on the Ten Commandments: Biblical scholarship and the art of disputation, pp. 623-644; Barbara FAES DE MOTTONI, Le «raptus» dans les «Quaestiones theologiae» d'Etienne Langton, pp. 645-666.

6 Les index des manuscrits cités, des auteurs anciens et médiévaux, des auteurs modernes et contemporains complètent le volume. 